\title{
FORMAÇÃO E PESQUISA: CONDIÇÕES E RESULTADOS
}

Julieta Beatriz Ramos Desaulniers*

SÍNTESE - Pretende-se expor algumas condiçōes necessárias para se instaurar um processo em que formação e pesquisa são indissociáveis, bem como os seus respectivos resultados, procurando salientar que essa alternativa pode representar uma ruptura na pedagogia que reforça as atitudes conformistas inscritas na própria lógica da reprodução escolar - que hoje constituem um dos principais obstáculos ao desenvolvimento da ciência social -, ao mesmo tempo que promove o fortalecimento do meio acadêmico e do contexto social em que está inserido.

\begin{abstract}
We intend to expose some conditions which are necessary in order to establish a process in which education and research, as well as their respective results, are inseparable. We try to point out that this alternative may represent a rupture in the pedagogy which reinforces the conformist attitudes that are inscribed in the logic of the school reproduction - attitudes which today constitute one of the main obstacles to the development of the social science -, and that, simultaneously, this alternative promotes the strengthening of the academic environment and of the social context in which it is located.
\end{abstract}

\section{1 - Considerações iniciais}

A questão que se coloca de imediato é a de saber como se constitui a relação entre formação e pesquisa, em especial, no campo acadêmico. Antes, porém, é importante tecer alguns comentários sobre a situação dessas instâncias junto à realidade universitária.

Para ser breve, poder-se-ia simplesmente dizer que a universidade tem como função essencial garantir a formação dos indivíduos que a ela recorrem, tendo como pilares para concretizar tal meta o ensino, a pesquisa e a extensão.

Esse tipo de caracterização, no entanto, oculta visões e representações que tendem a ser excludentes entre si no tocante à posição ocupada por cada um desses pilares que configuram a universidade e também quanto ao tipo de vinculação que estabelecem com a formação que ai se produz, e que podem ser traduzidas nos seguintes termos:

* Professora e pesquisadora junto ao Instituto de Filosofia e Ciências Humanas e ao Mestrado em Serviço Social da PUCRS.

\begin{tabular}{|l|l|l|l|l|l|}
\hline VERITAS & Porto Alegre & v. 42 & $\mathrm{n}^{2} 2$ & Junho 1997 & p. 183-204 \\
\hline
\end{tabular}


- priorizar o ensino é suficiente para a universidade atingir um resultado satisfatório junto à sua clientela, por se entender que esse é o tipo de formação que nela se espera obter. E as outras esferas - pesquisa e extensão -, caso seja possivel, podem funcionar como atividades esparsas sem estarem diretamente vinculadas à formação acadêmica proposta;

- o ensino é a esfera que polariza as atividades acadêmicas, e as iniciativas voltadas à pesquisa e à extensão assumem um caráter suplementar. A formação aqui continua sendo associada mais especificamente ao ensino;

- o ensino ocupa grande parte das atenções da instituição universitária, mas são bastante significativos os esforços para reduzir essa distorção - tão acentuada, em especial em nosso país -, os quais se materializam através de inúmeros apoios e estratégias que visam dinamizar a extensão e a pesquisa na universidade, considerados âmbitos de formação tão importantes quanto o ensino.

O que se verifica, em geral, é que a formação universitária vem sendo desenvolvida enquanto um processo que se constrói basicamente através do ensino. A pesquisa tem, na melhor das hipóteses, ocupado alguns espaços relativamente mais importantes que a extensão, mas excepcionalmente se equipara à posição que o ensino desfruta na universidade. E, mais raro ainda, é a pesquisa ser considerada e desenvolvida como a esfera que vitaliza e revitaliza o ensino e a extensão. Essa visão sustenta-se numa política de fomento constante à pesquisa, em que o processo de formação de pesquisadores representa uma alternativa fundamental para dinamizar o meio acadêmico. É, assim, que a universidade, ao cumprir com um dos seus compromissos com a sociedade, produz o "interesse" que significa a razão da sua própria existência.

Por isso, mesmo se a realidade universitária nem sempre dispõe das condições e estratégias capazes de materializar a relação entre formação e pesquisa, ela é fundamental. Aliás, para a universidade ser considerada um empreendimento em que vale a pena investir - porque os meios necessários para produzir uma relação de cumplicidade ontológica entre as estruturas mentais e as estruturas objetivas do espaço social em que está inserida estão sendo acionados - é indispensável que nela se estimulem e se mantenham iniciativas que tenham possibilidades de assegurar e mesmo fortalecer a pesquisa. ${ }^{3} \mathrm{E}$, obviamente, a dinâmica universitária

Pierre Bourdieu utiliza essa categoria para assinalar que cada campo social, seja o campo político, o campo religioso, o campo científico, ao se produzir, produz uma forma de "interesse" - ou de illusio, investimento ou libido, noções mais rigorosas conforme o próprio autor -, que é incorporado pelos seus membros e funciona enquanto instrumento de construção da realidade e de princípios de visão e divisão do universo no qual eles se movem. In: BOURDIEU, P. Razōes práticas - sobre a teoria da açäo. Campinas: Papirus, 1996 (Cap. 5).

2 Idem, p. 151

3 Segundo de Meis, "costuma-se dizer que a ciência brasileira é de baixa qualidade, que não damos para a coisa. Mas os dados mostram que o Brasil segue uma tendência mundial. O que temos é pouca gente trabalhando e pouco investimento na área". Comentários apresentados no jornal FoIha de São Paulo, 02/02/97, caderno 5, p.13, ao analisar o livro que publicou recentemente em coautoria, onde está demonstrado que a produção cientifica brasileira e sua repercussão cresceram entre 1981 e 1993 In: DE MEIS, Leopoldo \& LETA, Jacqueline. O perfil da ciência brasileira. RJ: Editora UFRJ, 1996. 
orientada segundo essa prioridade supõe o desenvolvimento de propostas que tenham como fundamento pedagógico a formação de pesquisadores, já que é dessa forma - produzindo os agentes desse processo - que poderá ocorrer a produção do "interesse", tanto da universidade quanto das demais esferas sociais, que apostam na expansão e especialmente na descoberta de novos saberes cientificos.

Pretende-se expor a seguir, algumas das condições que são necessárias para se instaurar um processo em que formação e pesquisa são indissociáveis e os seus respectivos resultados, procurando destacar que essa alternativa pode representar uma ruptura na "pedagogia corrente que reforça as atitudes conformistas inscritas na própria lógica da reprodução escolar", que se "constituem hoje o principal obstáculo que se levanta ao desenvolvimento da ciência social”.

\section{2 - Sobre as condições}

\section{1 - Construir o habitus científico}

Agora, cabe tecer algumas considerações sobre como a relação entre formação e pesquisa pode constituir-se uma estratégia que detém inúmeras possibilidades de manter e revitalizar o capital que distingue o campo científico $0^{5}$ no qual se situa a universidade. Segundo autores que se preocuparam com essas questões, como Bachelard, "talvez em nenhuma outra época o espírito científico tenha tido tanta necessidade de ser defendido quanto hoje[...]", destacando que "o amor pela ciência deve ser um dinamismo psíquico autógeno. No estado de pureza alcançado por uma psicanálise do conhecimento objetivo, a ciência é a estética da inteligência".

Nessa perspectiva, o resultado que se espera de uma formação dinamizada pela pesquisa é a produção do conhecimento científico que, em alguma medida, depende da forma pela qual está sendo realizada a sua própria reprodução. Tal processo sustenta-se na construção de um habitus científico, que é "o princípio gerador das estratégias que permitem aos agentes defrontarem-se com situações muito diversas", assumindo "a forma de um conjunto de relações históricas

4 BOURDIEU, P. O poder simbólico. Lisboa: DIFEL, 1989, p. 46.

${ }^{6}$ Essas categorias - campo e capital - são inteiramente interdependentes entre si. Um campo, em termos analíticos, "pode ser definido como uma rede, ou uma configuração de relações objetivas entre as posições. Essas posições são definidas objetivamente em sua existência e pelas determinações que elas impõem aos seus ocupantes, agentes ou instituições, devido a sua situação atual ou potencial na estrutura da distribuição das diferentes espécies de poder (ou de capital), onde a posse comanda o acesso aos interesses específicos que estão em jogo no campo, e, ao mesmo tempo, pelas suas relações objetivas com as outras posicões (dominação, subordinação, homologia, etc.)." In: BOURDIEU, P. Réponses - pour une anthropologie réflexive. Paris: Seuil, 1992, p. 76 e 77 (Trad. da autora). No campo científico, como è o capital intelectual que está em jogo, "é preciso munir-se de razão para ganhar. Sem produzir ou atrair super-homens, inspirados por motivações radicalmente diferentes dos homens comuns, ele produz e encoraja, por sua lógica própria, e à margem de qualquer imposição normativa, formas de comunicação particulares, como a discussão competitiva, o diálogo crítico, etc., que tendem a favorecer de fato a acumulação e o controle do saber". In: BOURDIEU, P. Coisas ditas. SP: Brasiliense, 1990, p. 46.

6 BACHELARD, Gaston. A formação do novo espírito científico. RJ: Contraponto, 1996, p. 13. 
“depositadas" nos corpos individuais sob a forma de esquemas mentais e corporais de percepção, de apreciação e de ação".?

Bourdieu aponta as principais atitudes ou disposições que constituem o processo de formação para e pela pesquisa - que possibilita a construção do habitus científico - que estão resumidas a seguir: ${ }^{8}$

- apreender a pesquisa como uma atividade racional - e não como uma espécie de busca mística, de que se fala com ênfase para se sentir confiante - mas que tem também o efeito de aumentar o temor ou a angústia: esta postura realista - o que não quer dizer cínica - está orientada para a maximização do rendimento dos investimentos e para o melhor aproveitamento possivel dos recursos, a começar pelo tempo de que se dispõe;

- pensar relacionalmente, pois se é verdade que o real é relacional, pode acontecer que nada se saiba de uma instituição acerca da qual se julga saber tudo, porque ela nada é fora das suas relações com o todo;

- aceitar correr riscos, pois é um discurso em que "a gente se expõe";

- participar efetivamente de um trabalho de pesquisa para se fazer uma idéia do que se passa na intimidade do "laboratório", ou da oficina: com todas as hesitações, todos os embaraços, todas as renúncias, etc.;

- problematizar o objeto a ser pesquisado a partir das suas rupturas, pois para se fazer progredir a ciência é preciso renunciar às grandes filosofias do devir histórico e instalar-se na descontinuidade;

- colocar em jogo "coisas teóricas" muito importantes a respeito de objetos ditos "empíricos" muito precisos, freqüentemente menores na aparência, e até mesmo um pouco irrisónios - ou seja, construir objetos socialmente insignificantes em objetos científicos;

- converter problemas muito abstratos em operações científicas inteiramente práticas, o que supõe uma relação muito especial com o que se chama geralmente de "teoria" ou "prática", implicando a construção de um objeto de pesquisa: um trabalho de grande fôlego, que se realiza pouco a pouco, por retoques sucessivos, por toda uma série de correções, de emendas, sugeridas pelo que se chama o ofício, quer dizer, esse conjunto de princípios práticos que orientam as opções ao mesmo tempo minúsculas e decisivas;

- rejeitar a divisão entre "teoria" e "metodologia", pois as opções técnicas mais "empiricas" são inseparáveis das opções mais "teóricas" de construção do objeto;

- praticar a dúvida radical para romper com o senso comum e também para evitar as aparências da cientificidade, contradizendo se necessário as normas em vigor e desafiando os critérios correntes do rigor cientifico, pois para fazer avançar a ciência, é preciso freqüentemente correr o risco de não se ter todos os sinais exteriores da cientificidade;

- observar e praticar para adquirir o modo de produção científico que supõe um modo de percepção, um conjunto de princípios de visão e de divisão,

BOURDIEU, P., op. cit. p. 24 e 25 (1992).

Mais detalhes sobre essas questões In: BOURDIEU, P. op. it. cit., p. 17 a 58, (1989). 
que "reage" perante operações práticas - um tipo de amostragem, um questionário. Esses "saberes" transmitem-se de prática a prática, por modos de transmissão totais e práticos, firmados no contato direto e duradouro entre aquele que ensina e aquele que aprende;

- dominar o saber adquirido da área ou disciplina em que se situa a pesquisa, já que a propensão para uma apreensão modesta das capacidades científicas do pesquisador só pode crescer à medida que cresce o conhecimento do que mais recentemente foi adquirido em matéria de métodos, de técnicas, de conceitos ou de teorias;

- exercitar a objetivação da relação que se estabelece com o objeto, visto que é a condição da ruptura com a propensão para investir no objeto, que está sem dúvida na origem do seu "interesse" pelo objeto.

Nessa perspectiva, o desenvolvimento das atividades acadêmicas, tendo na pesquisa o seu pólo dinamizador, exige a implementação de uma série de empreendimentos, dentre os quais a organização de uma linha de pesquisa bastante abrangente que esteja estruturada em referenciais teórico-metodológicos capazes de, por um lado, analisar a temática escolhida a partir da captura de elementos que expressam a sua complexidade e, por outro, articular o maior número possível de iniciativas de cunho investigativo que se situem ou disponham de aspectos para se associar ao âmbito da referida linha de pesquisa, a fim de se atingir um ponto de vista que seja suficientemente amplo para propiciar uma compreensão mais aproximada do fenômeno que está sendo o objeto de pesquisa.

Desse modo, algumas condições favoráveis para se desencadear a articulação entre formação e pesquisa - uma possibilidade ímpar de construção do habitus científico - estão colocadas à disposição dos agentes que interagem no meio acadêmico, que asseguram minimamente o rigor científico indispensável para se realizar pesquisa, assim como está proposta uma dinâmica que pode constituir-se no espaço possivel para a produção da pesquisa e do pesquisador, visto que pode funcionar como uma espécie de oficina onde se encontram as principais ferramentas para apreender e empreender um ofício, um métier: 0 ato de pesquisar.

Com o intuito de explicitar mais claramente as razões e as implicações oriundas de um trabalho que procura estabelecer uma estreita relação entre formação e pesquisa, exponho a seguir como venho construindo esse processo através da organização da linha de pesquisa intitulada Formação, Trabalho, Instituição. Estou bem consciente de que tal empenho não é nem exemplar e, muito menos, pioneiro. No entanto, com tal propósito, tenho a expectativa de, ao socializar os aspectos mais importantes dessa caminhada, estender as possibilidades da própria relação entre formação e pesquisa, além de conquistar uma maior clareza quanto à dinâmica da linha de pesquisa no seu conjunto.

$\mathrm{E}$, é claro, além de tudo isso, vale destacar que o próprio ato de produzir esse texto é uma das formas insubstituiveis de se materializar a relação entre formação e pesquisa, visto que, enquanto pesquiso estou formando-me e, à medida que vou aprimorando o meu desempenho nesse métier, disponho de novas possibilidades para estender e aprofundar as atividades ligadas à pesquisa. 
A temática que deu origem à linha de pesquisa em questão está associada às buscas feitas para elaborar a dissertação.' Em contato com o orientador, obtive informações sobre um projeto em andamento, do qual ele fazia parte, sobre a Formação da classe trabalhadora no Rio Grande do Sul, e que seria possível desenvolver a minha dissertação vinculada a esse projeto. Em seguida aceitei a idéia, que me pareceu muito oportuna, visto que me permitia ganhar tempo e qualidade no trabalho que precisava realizar. Afinal, poderia participar de um processo de pesquisa mais amplo, além de poder contar com a experiência de pessoas que já tinham mais intimidade com a temática e com o próprio métier.

Após concluir o mestrado, elaborei vários subprojetos de pesquisa relacionados com a formação dos trabalhadores no Rio Grande do Sul, os quais foram desenvolvidos com o auxilio de bolsistas de Iniciação Científica financiados pela PróReitoria de Pesquisa e Pós-Graduação da PUCRS. Os estudos e pesquisas realizados até meados de 1988 permitiram uma maior aproximação com o fenômeno que estava investigando e, assim, tive condições de verificar que vários segmentos sociais estavam interessados na formação dos trabalhadores, e que os processos que eles propunham para atingir tal meta estavam diretamente associados aos interesses dos seus respectivos representantes.

Em função disso, e instigada por algumas pistas fornecidas pelo orientador da dissertação" referentes a atividades da Igreja Católica relacionadas com a formação de futuros trabalhadores, procurei obter mais detalhes sobre isso. Num levantamento inicial que realizei - através de visitas a escolas católicas, entrevistas com ex-alunos e padres ou irmãos que atuaram em tais escolas, documentos e algumas fotos - foi possível verificar que havia muito a descobrir sobre a atuação dessa esfera social no tocante à formação de segmentos populares.

Sendo assim, elaborei um projeto - aprovado pela FAPERGS em meados de 1988 - que visava reconstituir o processo de formação desencadeado pelas escolas de ofício católicas que se localizavam em Porto Alegre, Rio Grande do Sul, no período de 1895 a 1970. Esse mesmo projeto, com algumas reformulações, foi apresentado ao comitê de seleção para o ingresso no doutorado em educação, da UFRGS. A partir desse momento, ampliaram-se significativamente as possibilidades para se instaurar rupturas decisivas em relação ao meu habitus científico, que até o momento apresentava inúmeras lacunas que colocavam em risco uma das condições indispensáveis para se fazer pesquisa: o rigor científico.

Efetivamente, inúmeras oportunidades contribuíram para o aprimoramento do projeto e me permitiram uma melhor compreensão dos procedimentos básicos que

- O título da dissertação é "Trabalho e socialização na Colônia Alemã de São Leopoldo/RS (182418460)", defendida em dez/1984 junto ao Mestrado em Sociologia/PUCRS, sob a orientação do Dr. Nilton Bueno Fischer (UFRGS).

is O contato com o orientador continuava bastante regular, mesmo após ter concluido a dissertação, devido a vinculação das minhas investigações com o seu projeto de pesquisa. Aliảs, o seu interesse e algumas orientações quanto ao ato de pesquisar representaram apoios importantes para me decidir a ingressar no doutorado. 
fazem parte desse métier, para se romper com o senso comum e, assim, captar o fenômeno enquanto uma teia complexa de relações.

A própria elaboração da tese, que exige o envolvimento do doutorando em diversas atividades, constituiu-se em uma das oportunidades de aprendizagem mais significativas para o meu processo de formação enquanto pesquisadora, bem como ao aprofundamento da temática que estava sendo por mim investigada. Isso porque foi capaz de instaurar uma ruptura no tipo de abordagem que eu estava propondo à temática em análise, que resultou na construção de um referencial teórico-metodológico a ser utilizado para pesquisar os processos de formação instaurados em escolas católicas, em especial, mas que pode ser utilizado para investigar qualquer processo de formação, desde que sejam inseridas em tal modelo as devidas especificidades do objeto a ser analisado a partir desse ponto de vista.

À medida que os estudos e pesquisas sobre tal temática foram-se ampliando - através de subprojetos desenvolvidos por bolsistas ou orientandas (da graduação ou do mestrado), de intercâmbios com pesquisadores que se interessam por essa questão (brasileiros e estrangeiros) e de atividades ligadas ao ensino e à extensão - fez-se necessánio encontrar uma forma capaz de articular todas essas atividades. A alternativa encontrada foi a organização de uma linha de pesquisa sob a denominação Formação, Trabalho, Instituição, que constitui o eixo articulador do conjunto de iniciativas desenvolvidas com base no referencial de análise utilizado para enfocar as questões relativas à formação em escolas católicas que, como já mencionei anteriormente, pode ser aplicado a processos de formação em geral.

Nessa perspectiva, vale observar que esse referencial já vem sendo utilizado para investigar vários processos de formação que se desenvolvem em outros campos sociais, propostos por estudantes de cursos de graduação ou de pósgraduação, que têm interesse em se associar a essa linha de pesquisa - alguns resultados relativos a tais pesquisas constam nesta publicação. As principais razões desse interesse dizem respeito ao tipo de temática em que se centra a referida linha de pesquisa, mas especialmente devido às possibilidades pedagógicas que tal opção pode representar em termos de uma maior clareza e definição, quanto aos mais variados problemas que esses estudantes serão obrigados a enfrentar na realização de uma monografia ou dissertação. Trabalhos, aliás, que supõem uma postura que eles estão apenas começando a assumir, faltando-lhes ainda toda uma caminhada nessa direção, para que se instaurem as principais disposições que caracterizam o habitus científico.

Ainda, sobre a temática e o respectivo referencial utilizado, é importante assinalar que ambos foram redimensionados quando se articularam ao Projeto Integrado, já mencionado anteriormente, visto que a formação em escolas de ofício católicas passou a ser enfocada numa perspectiva interdisciplinar, com 0 intuito de capturar a produção do cidadão gaúcho que se foi constituindo no decorrer do século XX, juntamente com a reconstituição de outros processos formativos que desempenharam um papel importante nesse empreendimento."

"Outros detalhes In: PI "Urbanidade e cidadania: processos de formação e de instauração de saberes", financiado pelo CNPq e pela FAPERGS. 
Apresenta-se, a seguir, a problemática que se constitui o suporte para a referida linha de pesquisa, que inclui o problema, a conceituação das principais categorias de análise utilizadas e o sistema de hipóteses proposto ao se construir tal objeto de pesquisa. Devido aos limites deste artigo, os comentários mais detalhados sobre as referências teóricas que subsidiam essa abordagem, assim como sobre a metodologia - entendida como materialização da teoria - não serão aqui expostos. ${ }^{12}$

\subsection{1 - A problemática da pesquisa}

Observa-se que o processo de formação sofreu mudanças no decorrer do tempo, de acordo com as necessidades do mundo atual. Exige-se, desde as últimas décadas, uma formação a ser realizada em moldes globalizantes ${ }^{13}$ (mais flexível e respeitando princípios democráticos), ao invés do que ocorria até a metade desse século, quando tal processo tinha um cunho totalizante (baseado na rigidez e no autoritarismo).

Ainda é importante frisar que, quanto mais diversificados forem os meios de obtenção de saberes, maior será a eficácia da instituição escolar enquanto produtora da sociedade, já que são os saberes construidos no espaço escolar, juntamente com a forma pela qual se instaura esse processo, os principais elementos que constituem a formação/produção de seus agentes e, conseqüentemente, da sociedade de que os mesmos fazem parte. Sendo assim, reconstruir a formação que é produzida em uma instituição escolar implica, também, caracterizar os principais saberes que foram sendo privilegiados nesse contexto e verificar em que medida tal processo instaura competência (o "saber-ser") e qualifica (o "saberfazer") os seus formados, para o desempenho de uma profissão.

Tais ponderações são indispensáveis quando se pretende verificar como se tem constituído a formação instaurada em escolas católicas do Rio Grande do Sul, em especial aquelas que se ocupavam dos filhos de trabalhadores, a partir de meados do século XIX. A seguir, serão apresentados os principais elementos das categorias de análise consideradas centrais nessa pesquisa.

\section{A concepção de formação}

Os termos formação, formar, formado (a) derivam-se do termo forma que, em latim, significa "molde ou meio pelo qual se dá a uma certa matéria a forma que se deseja"." Formação é a ação pela qual algo se forma, é produzido; é a ação de formar, de organizar, de instituir, de instruir, de educar e seu resultado. E formado (a) é aquele (a) que recebeu uma certa forma; que foi habituado conforme tal forma ou tal feitio. ${ }^{15}$

12 Essas informaçōes encontram-se detalhadas In: DESAULNIERS, Julieta Beatriz Ramos. "Trabalho: a escola do trabalhador?" Tese de doutorado, defendida junto ao PPGEd/UFRGS, maio/1993.

13 Outras considerações sobre esse tipo de formação constam a seguir, nas páginas 10,11,12 e 13.

14 FOULOUIÉ, Paul. Dictionnaire de la langue pédagogique. Paris: Presses Universitaires de France, 1971, p. 222.

16 Dictionnaire Encyclopédique Quillet. Paris: Librairie Aristide Quillet, 1979, p. 2561. 
Esse conceito envolve a aquisição de inúmeros conhecimentos, não se confundindo, porém, com instrução, já que o processo de formação implica o desenvolvimento de habilidades e atitudes, assim como a integração dos saberes à prática cotidiana da vida do formado. ${ }^{16}$

Em outras palavras, "toda formação supõe uma reflexão sobre o sistema de valores que a fundamenta e requer que se coloque em ação aquilo que foi adquirido, de maneira teórica e prática. É a pessoa inteira, nos fundamentos da sua própria personalidade, que é envolvida pelo ato de formação"."

Observa-se que, mesmo fortemente condicionado pelos elementos referenciais do mundo religioso e da própria instituição, o processo de formação realizado em escolas de ofício católicas não excluiu a ação dos indivíduos que nele estavam envolvidos e, como todo processo ativo, caracterizou-se também por "um movimento de autofazer-se", permeado de "relações encarnadas em pessoas e contextos reais", constituindo-se em um processo histórico. ${ }^{18}$

É evidente também que tais escolas, na condição de instituição, ao formar, reproduziam os aspectos sociais que lhe davam sustentação. Mas, como a reprodução jamais é perfeita, pois sempre existe "uma tendência em direção a um compromisso com circunstâncias históricas específicas, e é nesta descontinuidade que a produção é possível, que a agência humana tem espaço para se movimentar", ${ }^{19}$ também a referida formação conta, no decorrer do seu processo, com a dimensão da produção.

$O$ fato de num mesmo ambiente conviverem pessoas com diferentes habitus (sistema de disposições adquiridas), oriundos de diferentes contextos, viabilizou a mudança, a ruptura e não apenas o consenso. E se entende que esse processo de formação visava, principalmente, instaurar um novo habitus, para constituir o principio gerador de respostas, mais ou menos adaptadas às exigências da instituição e do contexto social. ${ }^{\text {}}$

Como fenômeno que se constitui historicamente, tal processo recebeu também influências dos vários setores da sociedade e dos seus poderes, mesmo no período em que essas instituições eram bastante fechadas. É possível então que, no decorrer da trajetória aqui considerada, a formação instaurada em tais escolas, apresente dimensões novas, diferentes e até opostas ao processo inicialmente proposto, justamente em função dessas interferências externas, que foram, sabiamente, canalizadas pelo poder dos seus responsáveis, em vários momentos.

Nas últimas décadas, a concepção de formação tem sido muito utilizada, em especial nos estudos que se referem às questões ligadas a trabalho e educação. Mais recentemente, Empson e outros estudiosos consideram que o termo formação diz respeito não somente às organizações como Estado, Igreja, Forças Arma-

16 LEGEDRE, Renald. Dictionnaire actuel de l'éducation. Paris: Larousse, 1979, p. 232.

17 MIALARET, Gaston. (Dir). Vocabulaire de l'éducation. Paris: Presses Universitaires de France, 1979, p. 232. (trad. da autora).

1 THOMPSON, E. P. A formação da classe operánia inglesa - a árvore da liberdade. Rio de Janeiro: Paz e Terra, 1987, p.9.

10 HARKER, Richard K. Reprodução, habitus e educaçăo. In: Teoria \& Educaçăo. Porto Alegre: Palmarinca, $n^{2} 1,1990$, p. 84.

¿ BOURDIEU, P. Coisas Ditas. São Paulo: Brasiliense, 1990. p. 131. 
das, escola, empresa, mas também aos movimentos de familia, de jovens, de grupos de lazer e assim por diante. Ou seja, não é mais só "a questão do trabalho, da produção e do poder que está em causa, mas o conjunto da vida, da totalidade das relações humanas". ". Além disso, considera-se que, no desenvolvimento de atividades de formação, há a incorporação de aspectos particulares, freqüentemente coloridos de práticas originais. ${ }^{n}$

Obviamente, a concepção de formação vem assumindo conotações específicas, em diferentes tempos e espaços históricos, visto que se refere a uma construção social. É em função de uma constante recomposição dos saberes exigidos pelo mundo do trabalho que o processo de formação, atualmente, visa ao "ajustamento ao mundo e, na medida em que se trata de um mundo em constante mudança, à adaptação a essa evolução". ${ }^{3}$ Assim, as novas exigências impostas à atuação profissional demandam conteúdos relativos à ordem social, que podem ser adquiridos nos diversos espaços e tempos vividos pelo individuo.

Estudos recentes têm demonstrado, inclusive, que toda a ação humana, mesmo aquela extraída de uma experiência rotineira, implica um certo grau de qualificação, resultando sempre em alguma competência. Isso significa dizer que o saber passa a assumir um atributo de sujeito, e que "a relação cognitiva tende a se definir sobre o modo de ser (ser competente) e não mais sobre aquele de ter (ter um saber com o risco de perdê-lo) a qualificação"."

A partir dessas colocações, verifica-se que a formação globalizante baseia-se na instauração da competência, mais centrada no "saber-ser", do que no "saberfazer", e implica dizer que trabalhador competente é aquele que sabe utilizar de maneira eficaz todos os seus conhecimentos, nas mais diversas situações encontradas em seu posto de trabalho.

Esse "saber-ser" constitui-se também de saberes tácitos, informais. Ou seja, envolve boa parte de conhecimentos ditos "arbitrários" - conhecimentos que não têm uma ligação direta com os saberes do métier do trabalhador - e que são, por isso, de difícil aferição e mensuração.

Atualmente, é consensual a idéia de que a formação de competências poderá ser ampliada, quanto mais se relativizarem "as oposições entre saber formal e informal, saber teórico e prático" ou entre saber e saber-fazer, como também "as distinções entre as formas rígidas e as práticas informais" de obtenção de saber. ${ }^{25}$

Efetivamente, o fenômeno em estudo, como de resto toda a vida social, constitui-se a partir de "uma infinidade de interações, todas muito precisamente localizadas no tempo e no espaço". Neste sentido, é importante conhecer, o mais exatamente possível, as circunstâncias e o lugar em que esse processo de formação foi produzido.

21 EMPSON, apud TANGUY, Lucie (Org). L'introuvable relation formation/emploi. Paris: La Documentation Française. 1986, p. 100. (trad. da autora).

$n$ TANGUY, op. cit. , p. 100.

FOULQUIE, op. cit., p. 233. (trad. da autora).

STROOBANTS, op. cit., p. 36.

¿ Idem. p. 37.

26 ACCARDO, op. cit., p. 33. 
A formação oferecida aos futuros trabalhadores, e que está sendo investigada a partir do referencial aqui exposto, realizou-se numa escola - um espaço concreto permeado de relações sociais, com uma base material e uma gestão específicas. Ou seja, trata-se de um fenômeno produzido em um espaço institucional. Por isso, torna-se indispensável mencionar aqui as dimensões privilegiadas neste estudo, que configuram a escolarização enquanto um fato institucional. ${ }^{z l}$

Visto que o principal pressuposto é o de que a instituição escolar resulta de um conjunto de relações sociais, que se instauram a partir de uma base material e de gestão, é primordial analisar o funcionamento da instituição, considerando os seus aspectos materiais e administrativos, bem como as práticas, os interesses e as categorias de interpretação dos diversos grupos de agentes que a compõem. ${ }^{\text {r }}$

É importante distinguir "os comportamentos profissionais e sócio-políticos do pessoal da instituição e a política escolar aplicada ou exigida pelo governo e, ain-

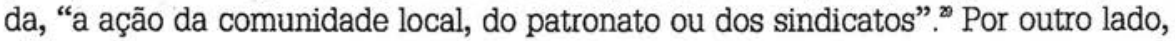
as vagas oferecidas pelos estabelecimentos constituem a mediação institucional principal, pela qual as propriedades da estrutura de classe, as políticas escolares ou outros fatores conjunturais se traduzem em fatos de escolarização. Por isso, a oferta de vagas deve ser analisada em função dos determinantes pedagógicos, espaciais e financeiros, considerando também os fatores que condicionam a demanda e a concorrência quanto às vagas existentes.

\section{O sistema de hipóteses}

Conforme o que já foi exposto até aqui, a descontinuidade verificada na gênese e estruturação das escolas de ofício católicas, como também na formação que estas propunham aos filhos de trabalhadores, está associada à dinâmica estrutural do campo religioso e à sua articulação, ao mesmo tempo interativa e conflitiva, com a dinâmica estrutural dos campos social, econômico e político, no decorrer do tempo.

A partir dessa articulação, que é central na pesquisa, podem-se formular estas hipóteses:

a) A interação entre a dinâmica dos campos religiosos e sócio-econômicopolítico determina o surgimento de um novo discurso religioso, organizado em torno de um meio operacional (a escola de ofício católica), portador de certos elementos que se diferenciam dos discursos religiosos anteriores (interesse pelas massas populares, posição do homem frente à natureza, significado do trabalho), e que foi tendo suas bases de sustentação reduzidas, com o passar do tempo.

b) $\mathrm{O}$ novo discurso religioso instaura-se a partir de um sistema de relações que possibilitou sua inserção em espaços ainda não ocupados de forma significativa por outros segmentos sociais, produzindo representações vinculadas à dinâmica

z)

m

$\approx$

CHAPOULIE, Jean-Michel \& BRIAND, Jean-Pierre, op. cit. p. 13.

CHAPOULJE, Jean-Michel \& BRIAND, Jean-Pierre. L'évolution de la scolarisation pós-obligatoire: un schéma d'analyse. In: Réflexions Historiques. Vol./Tome 7, 1980, p. 23.

Idem, p. 28. 
estrutural dos campos social, econômico e político, com os quais foi estabelecendo relações, indispensáveis à sua constituição. 0 tipo e a forma de inserção desse discurso - os aspectos resultantes das trajetórias desses campos em luta entre si passam a ser questionados e tendem a entrar em crise.

c) As representações produzidas pelo novo discurso articulam-se a certos esquemas e práticas sociais, a partir da dinâmica estrutural dos campos religioso e sócio-econômico-político, possibilitando a gênese e a expansão dessa escola de ofício católica, que formava segmentos da classe trabalhadora, com base nos fundamentos da doutrina católica. Com o passar do tempo, esse tipo de escola não produzia mais os resultados esperados pelo sistema sócio-econômico-político vigente.

d) A articulação, resultante da dinâmica estrutural desses vários campos, baseia-se em representações associativas e conflitivas em relação aos setores sociais dominantes, as quais limitaram a dinâmica do novo discurso religioso no tocante à sua operacionalização - impondo adaptações, mudanças, adoção de novos elementos ou dimensões - e à formação propiciada pelas escolas de ofício católicas. Tal discurso foi reorientado no decorrer do tempo, não mais representando os aspectos que justificavam sua existência frente ao grupo ou classe social com a qual os agentes do campo religioso realizavam o trabalho de dominação, nesse momento.

e) As limitações impostas ao novo discurso religioso, a partir de novas exigências oriundas da interação entre os campos, com o passar do tempo, foram determinando a modalidade que, aos poucos, reestruturou o processo de formação implantado no Pão dos Pobres.

Como é o ponto de vista que cria o objeto, conforme Saussure, e não o contrário, procurou-se definir e construir o objeto de estudo ${ }^{x}$ aqui proposto, "em função de uma problemática teórica"”l que resultou no conjunto de hipóteses exposto anteriormente. Nesse sentido, os estudos de Pierre Bourdieu constituem uma referência importante para captar os mecanismos e relações que foram dominantes na construção da trajetória do processo de formação aqui investigado.

Em vista dos limites deste artigo, não será possivel entrar em maiores detaIhes, mas é oportuno, pelo menos, assinalar que a noção de campo é central no modelo proposto pelo referido autor. ${ }^{x}$ Ele destaca a relação entre campo e habitus - sistema de disposições adquirido na relação com um determinado campo - como a "única maneira rigorosa de reintroduzir os agentes singulares e suas ações singulares", sem incorrer na história factual. ${ }^{\text {" }}$

* Conforme Bourdieu, a construção do objeto, para ser realista, precisa apoiar-se num conhecimento anterior do fenômeno investigado. Somente assim, a pesquisa tem condições de fazer surgir as realidades que ela pretende registrar. In: BOURDIEU, P. \& Outros. La misère du monde. Paris: Seuil. 1993, p. 916. BOURDIEU, P. El oficio de sociólogo. Buenos Aires, Ed. Séc. XXI, 1978, p. 54.

$n$ Conforme o autor, tal noção tem sido útil "para designar uma postura teórica geradora de escolhas metódicas, negativas e positivas, na construção dos objetos." In: BOURDIEU, P. Les regles de l'art - genèse et struture du champ littéraire. Paris: Seul, 1992, p. 254.

3

BOURDIEU, P., op. cit., 1990, p. 63. 
O esquema apresentado a seguir expressa as principais relações entre a categoria central - o processo de formação em escolas de ofício católicas - e os outros elementos que a explicam e a determinam.

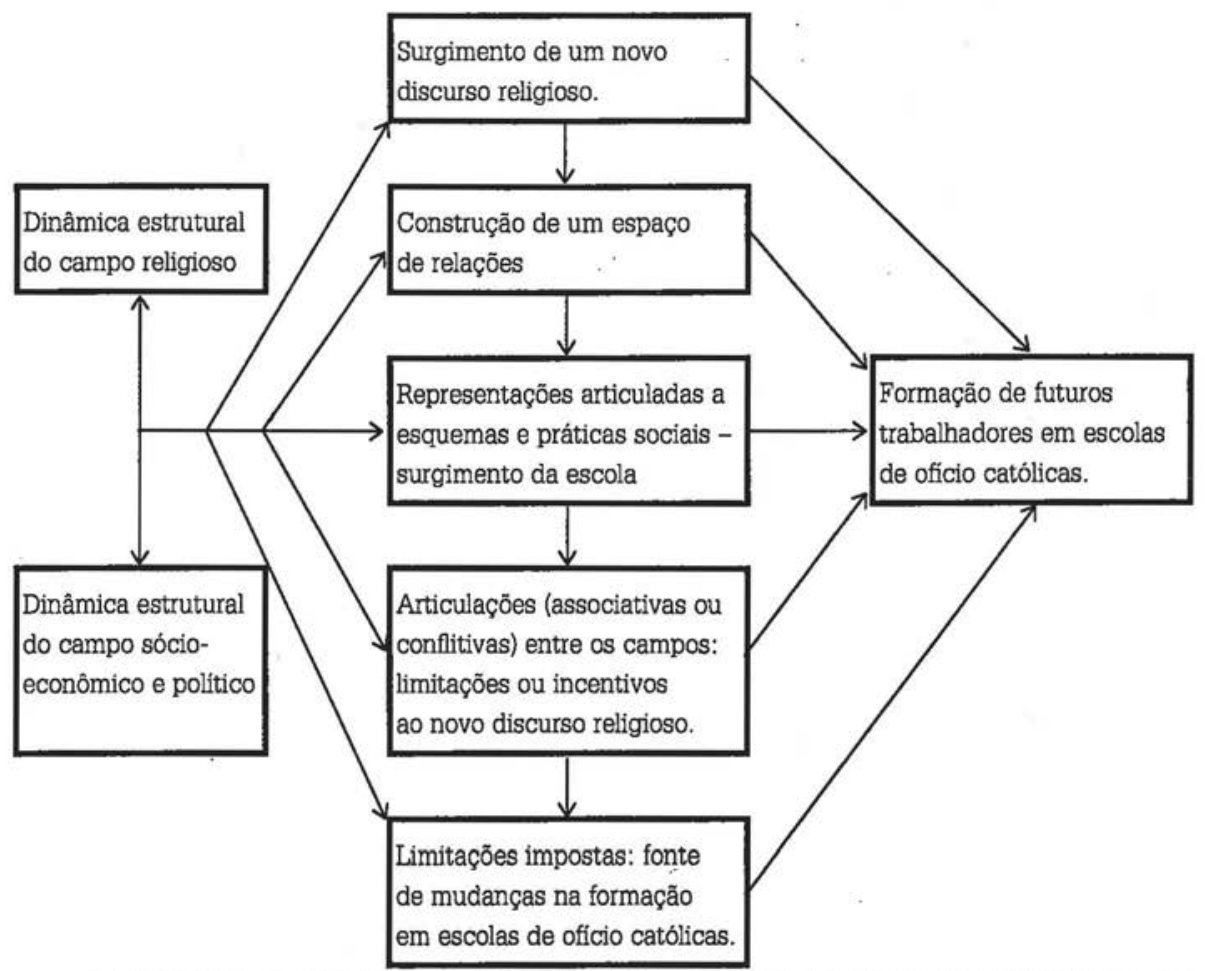

A definição e seleção dos conceitos, dimensões e indicadores, derivados do sistema de hipóteses, basearam-se nos referenciais mencionados até aqui. A operacionalização dos pressupostos teóricos através de tal procedimento exerceu o papel de uma "trilha" ou filtro que esclareceu, distinguiu e hierarquizou os elementos priorizados na análise do tecido de relações, constitutivos do fenômeno em estudo.

\section{3 - OS RESULTADOS}

\section{1 - Uma possibilidade de construção de futuros pesquisadores}

A única condição para participar regularmente das atividades propostas pela linha de pesquisa Formação, Trabalho, Instituição, enquanto membro da equipe, é a existência e a manifestação de algum tipo de interesse, seja ele ligado ao próprio ato de pesquisar ou ainda à temática em si que está sendo investigada. A partir daí, os interessados associam-se a essa dinâmica na condição de bolsista, orientando (da graduação ou pós-graduação) ou pesquisador. 
Há atividades e iniciativas a serem empreendidas, que são comuns ou então recomendadas a todos os associados. Outras, no entanto, são bastante específicas, de acordo com a condição do participante, a fim de se garantir o desenvolvimento de um processo que esteja o mais afinado possivel com as necessidades de cada integrante da equipe quanto ao aprendizado do métier.

Vale observar que várias iniciativas estão preocupadas com a divulgação dos principais resultados já obtidos nos levantamentos, bem como dos suportes teóricos mais importantes ao fortalecimento de tais investigações. Isso porque se parte do pressuposto de que todo saber é construído socialmente, o que significa dizer que, para se aprimorar o que está sendo apreendido, é fundamental que tal conjunto de saberes seja socializado, pois somente assim será, pelo confrontado com outras situações, colocado à prova quando, então, se poderá verificar a sua validade e pertinência.

Dentre as atividades comuns, destacam-se:

- leitura e discussão do projeto que contém o referencial da linha de pesquisa, bem como dos subprojetos em andamento e dos relatórios parciais e anuais que sistematizam os dados já colhidos com as investigações realizadas desde 1988;

- leitura e discussão dos artigos produzidos a partir dos levantamentos efetuados;

- leitura e discussão de textos ou obras que se constituem nas referências mais fundamentais desse empreendimento;

- participação dos encontros semanais - com programação divulgada no início de cada semestre letivo, o Agende-se, estando aberto a qualquer interessado - que funcionam como oficina de pesquisa, em que se propõem situações que favorecem a apropriação das ferramentas indispensáveis para a realização da pesquisa, que vão desde exposições sobre questões mais teóricas sobre pesquisa, até à realização de práticas que materializam a teoria, como a construção de um objeto de pesquisa ou de instrumentos (entrevista, questionário, etc.);

- participação de reuniões de estudo sobre assuntos relacionados com a temática da linha de pesquisa, que são planejadas antecipadamente;

- elaboração de relatórios parciais e finais sobre as atividades realizadas, bem como de artigos a serem apresentados em eventos científicos;

- participação de simpósios, congressos e outros eventos que se referem aos interesses de tais pesquisas, na condição de assistente e, sempre que possível, de apresentador de trabalho sobre alguns resultados obtidos;

- apropriar-se de algumas linguagens da informática que se constituem em instrumentos indispensáveis para o desenvolvimento dos vários subprojetos;

- cursar uma língua estrangeira, preferencialmente inglês ou francês, para ser capaz de ter acesso a temas recentes que são tratados pela literatura estrangeira;

- produzir alguns instrumentos a serem utilizados na coleta de dados;

- aplicar tais instrumentos junto às unidades que estão sendo pesquisadas; 
- participar da organização de cursos de extensão, encontros, palestras;

- colaborar na organização de exposição ou publicações, em todas as suas etapas, desde a digitação, seleção de material, até à produção de um artigo para ser apresentado ou então publicado;

- montar e editar um pequeno boletim - o InFormativo - contendo as principais informações relacionadas com a dinâmica da linha de pesquisa.

Enfim, é uma lista de iniciativas e atribuições que pode parecer impraticável, considerando-se o clima acadêmico reinante em nossas universidades, em que o habitus científico está bastante distante do nosso horizonte. E, precisamente por isso, é que se faz necessário um envolvimento intensivo, tanto do associado quanto do coordenador da linha de pesquisa, pois somente assim será possível estabelecer algumas rupturas em benefício de um habitus que se aproxime das disposições que configuram o habitus científico, conforme indicações feitas anteriormente, no item 2.1.

Ruptura aqui está sendo entendida como "uma conversão de olhar e pode-se dizer do ensino da pesquisa em sociologia" (e, em geral) "que ele deve em primeiro lugar "dar novos olhos" como dizem por vezes os filósofos iniciáticos. Tratase de produzir senão um "um homem novo", pelo menos, "um novo olhar". E, sendo mais incisivo ainda, Bourdieu observa que "isso não é possível sem uma verdadeira conversão, uma metanóia, uma revolução mental, uma mudança de toda visão do mundo social".

Essa é a razão para explicar uma certa austeridade que esse tipo de empreendimento pode transparecer, mas formar implica produzir novas formas e, em conseqüência disso, implica a negação de atitudes, incorporadas em tantas outras oportunidades, que se opõem às disposições relativas à postura que se associa ao habitus científico. Então, na verdade, sem a instauração dessa ruptura que resulte num "novo olhar" conforme palavras do autor acima citado, muito pouco se conquista em termos de formação associada à pesquisa - ou seja: na produção de novos pesquisadores.

Antes de mencionar as atividades ou atribuições específicas, de acordo com a situação de cada membro da equipe, salienta-se que todo esse processo, bastante árduo além de moroso, é acompanhado de encontros regulares com a coordenação, a fim de se assegurar uma ocasião em que se esclarecem dúvidas, além de ser uma oportunidade para se mensurarem as principais dificuldades ou vibrações que estão sendo vivenciadas pelo bolsista ou pelo orientando. Esse momento é, sem dúvida, absolutamente indispensável para a produção de tal processo. ${ }^{3}$

Por tudo isso, fica muito difícil discordar de Bourdieu quando ele diz que "só se pode realmente dirigir uma pesquisa, com a condição de a fazer verdadeiramente com aquele que tem a responsabilidade direta dela: o que implica que se trabalhe na preparação do questionário, na leitura dos quadros estatísticos ou na interpretação dos documentos, que se sugiram hipóteses quando for o caso disso,

\% BOURDIEU, P., 1989, p. 49

35 Sobre isso, Bourdieu diz que "o diretor de pesquisa, se quisesse cumprir verdadeiramente a sua função, deveria desempenhar por vezes o papel, efetivamente perigoso e em qualquer caso injustificável, de "diretor" de "consciência". In: BOURDIEU, P. op. cit., 1989, p. 50. 
etc. É claro que não se pode, nestas condições, dirigir verdadeiramente senão um pequeno número de trabalhos, e aqueles que declaram "dirigir" um grande número deles não fazem verdadeiramente 0 que dizem". ${ }^{.6}$

As atribuições que são indiscutivelmente mais exigentes, consistem na elaboração e realização de todas as etapas que envolvem o processo de pesquisa. Essa é uma tarefa de todo aquele que precisa produzir um trabalho de conclusão de curso (graduação), uma dissertação ou tese (pós-graduação) ou, na condição de pesquisador, desenvolver projetos ligados à sua área de interesse.

É certo que desenvolver um projeto vinculado a uma linha de pesquisa pode significar vantagens tanto para o associado quanto para a própria linha de pesquisa. Para o associado, porque ele dispõe de um ambiente que ao mesmo tempo que o estimula em suas apreensões e dificuldades quase incontornáveis, oferece-lhe parâmetros relativamente sistematizado para construir seu objeto de pesquisa e que vão instigar todo o processo. Além disso, ele tem a possibilidade de produzir um trabalho que se integra numa perspectiva mais ampla e, por isso, os seus resultados, ao invés de ficarem no esquecimento, podem ser muito úteis para se atingirem generalizações que permitam a confirmação dos saberes científicos já construídos ou a sua retificação.

É assim que a própria dinâmica da linha de pesquisa será beneficiada, já que a pesquisa, bem como o pesquisador estarão cumprindo o seu papel, do mesmo modo que o pesquisador, que é o de promover o avanço da ciência. E, evidentemente, o contexto acadêmico que tem o seu interesse diretamente dependente do capital científico tem, igualmente, as suas principais atribuições e necessidades satisfeitas, o que assegura - podendo inclusive expandir - o seu poder nas relações de disputa travadas entre os seus agentes e com os representantes dos demais campos sociais com os quais interage.

\section{2 - Uma possibilidade de construção de novos saberes cientificos ${ }^{3}$}

A experiência científica, na perspectiva da ciência moderna, é uma razão confirmada, "apreendida pela teoria antes de ser descoberta pela observação" . Sendo assim, mesmo se é o "objeto quem fornece os elementos à prova", o qual se apresenta "como um complexo de relações", a proposição de "juízos sintéticos a prion" é indispensável para se restituírem ao fenômeno todas as suas solidariedades e, ao mesmo tempo, "romper com o nosso conceito de repouso"."

A partir desses parâmetros que se procurou incorporar ao referencial de análise utilizado para investigar a instituição escolar - as escolas de ofício católicas, mais especificamente - foi possivel ultrapassar, em alguma medida, o nivel proposto por um simples diagnóstico, que se detém na descrição linear dos dados colhidos, por não dispor de uma problemática teórica que instigue e aprofunde a compreensão do fenômeno pesquisado.

\footnotetext{
Idem, p. 21.
}

3 Esse item, com algumas reformulações, consta em "Formação e instituição escolar", Revista Educação \& Realidade, Porto Alegre: Editora da UFRGS, vol. 21, n. 2, 1996.

BACHELARD, Gaston. O novo espirito cientifico. Porto: Saber, 1986, p. 18.

Idem, p. 14. 
Alguns dos resultados conquistados no decorrer da investigação realizada junto a uma das escolas de ofício investigadas - o Pão dos Pobres, localizado em Porto Alegre, Rio Grande do Sul - a serem apresentados a seguir, permitem inferir a complexidade que constitui esse fenômeno, ao mesmo tempo que rejeitam conclusões apressadas que tendem mais à ratificação do senso comum, do que à retificação de saberes já instituídos sobre o objeto de estudo - o principal meio para se garantir o avanço da ciência.

Inicialmente, vale assinalar que a descontinuidade verificada no processo de formação instaurado nessa escola, ${ }^{*}$ assim como no das demais escolas investigadas, torna-se mais compreensivel quando as explicações para tais rupturas estão associadas à dinâmica estrutural do campo religioso e à sua articulação, ao mesmo tempo interativa e conflitiva, com a dinâmica estrutural do campo social, econômico e político, no decorrer do tempo.

Nessa perspectiva, verifica-se que a formação desencadeada em escolas de ofício católica - um meio operacional de inserção do novo discurso religioso revelou-se eficiente enquanto foi capaz de mobilizar o capital caracteristico do campo religioso, estabelecendo através dele as lutas com os demais campos do espaço social, pela garantia e expansão do seu poder. Dessa maneira, tais obras tiveram reconhecido seu valor - incomensurável face aos interesses engendrados pelos outros campos - através de um conjunto de estratégias que visavam produzir uma forma específica de illusio ou interesse, assegurando para si legitimidade junto aos demais campos.

Assim, essas iniciativas asseguram a eficácia do processo que pretendia, em novos moldes, instaurar um sistema de disposições gerais, capaz de expressar a forma cristã que produziria o homem novo, "apto para o trabalho, que lhe garantiria uma vida útil para si e à Pátria, quando fosse reintegrado ao convívio social"."

Desse modo, as condições de sucesso das escolas católicas foram plenas, conforme as metas traçadas e as estratégias utilizadas, já que produziram os espaços e os tempos necessários para assegurar a formação concebida para provocar uma ruptura e estruturar um novo habitus junto aos futuros trabalhadores. Esse habitus significava o produto da incorporação da necessidade imanente do meio as escolas situadas no campo religioso - articulado a outros campos e, também, numa dinâmica de construção cognitiva.

As várias práticas da rotina dessas escolas que funcionaram em regime de internato até os anos setenta, realizadas em espaço fechado, juntamente com a vigilância permanente, representaram para o interno, entre outras coisas, uma fonte diversificada de aquisição de saberes estreitamente associados à moralidade cristã, de que o silêncio, a disciplina e o trabalho permanente constituiram o suporte, e lhe asseguraram alguma competência ("saber-ser").

* O Pão dos Pobres, de 1895 a 1916, foi ABRIGO para viúvas e seus filhos; de 1916 a 1930 instalou o ORFANOTRÓFIO para órfãos (em número de 50 meninos), com ênfase no ensino de conhecimentos gerais; de 1930 a 1970, transformou-se em LICEU (com capacidade para 300 carentes), visando a formação profissional dos internos, através da aprendizagem de um oficio.

41 Afirmação recorrente em documentos e discursos pronunciados pelos agentes que atuavam junto ao Pão dos Pobres, em especial depois da inauguração do Orfanotrófio, em 1916. 
Em termos gerais, o presente estudo permite concluir que o processo de formação de futuros trabalhadores revelou-se um eficiente meio de operacionalização do novo discurso proposto pela Igreja Católica, em fins do século XIX, através da Encíclica Rerum Novarum. No decorrer de seu percurso, tais instituições atingem seu objetivo último: o de garantir e ampliar o poder e a influência do campo religioso, junto aos vários setores do espaço social de Porto Alegre e mesmo do próprio Estado do Rio Grande do Sul.

As descobertas aqui referidas - conquistadas a partir dos estudos e pesquisas sobre instituições escolares católicas que se dedicavam à formação de segmentos populares até 1970 - devem-se primordialmente à utilização de um referencial teórico-metodológico de análise. Ele exerceu a função de instrumental ${ }^{12}$ que permitiu "destrinchar as circunstâncias que estão baralhadas" e, assim, reduziu as possibilidades de tomar a aparência do fenômeno como sendo a sua essência."

A partir dessa afirmação, podem-se tecer as seguintes considerações:

a) $\mathrm{O}$ referencial apresentado anteriormente auxilia a instigar $e$ a investigar 0 real em estudo - a formação em escolas católicas - mas também permite a captação das especificidades de outras instituições voltadas para a formação de alunos ou outros agentes, estejam ou não vinculados ao campo religioso, o que possibilita generalizações a respeito do tema em questão.

b) $\mathrm{O}$ fenômeno pesquisado não se explica por si mesmo ou, principalmente, pelos fatores externos a ele. Fica claro, nessa forma de aprendê-lo, que ele se constitui de uma "teia de relações", já que o real é sempre relacional;" que é no jogo de posições e tomadas de posições, baseado em relações de disputa travadas entre os agentes dos diversos campos do espaço social, que o processo de formação, bem como a estrutura da instituição escolar, vão-se estruturando, no decorrer do tempo. É nessa dinâmica que a formação instaurada em uma dada instituição, vai imprimindo a sua forma junto à sociedade em que está inserida e, assim, realiza sua função enquanto produtora do social.

c) As rupturas na trajetória das instituições pesquisadas não podem ser explicadas somente por um ou por outro aspecto que integra a realidade do respectivo campo social em que estão inseridas. Tem-se que incluir, em tal reconstituição, as principais razões que as constituem - tendo-se presente que sua existência resulta de um conjunto de relações sociais -, a fim de não se reduzir excessivamente a complexidade das mesmas.

\section{3 - Uma possibilidade de resgatar a memónia social}

A preservação dos diversos suportes da memória social tem despertado um interesse progressivo, por se entender que se trata de um importante instrumento para ampliar os "espaços de possibilidades" voltados à construção da cidadania. Por isso, iniciativas nesse sentido começam a multiplicar-se em nosso país, o que significa melhores condições à pesquisa histórica, além de novos subsídios à pró-

42 De acordo com Bachelard, "os instrumentos não são senão teorias materializadas. Delas saem fenômenos que trazem por todos os lados a marca teórica". In: BACHELARD, G. op. cit., p. 18.

43 Idem, p. 120.

"Idem, p. 106. 
pria produção social, que estarão sendo colocados ao dispor da sociedade em geral."

Essa iniciativa, aliás, precisa ser uma prioridade dentre as atividades realizadas pelo pesquisador, pois a conquista de descobertas através da pesquisa não é uma tarefa fácil. Muito pelo contránio. Reunir e organizar os "achados" demanda um trabalho muito árduo, além de exigir uma postura flexivel do pesquisador face aos tantos "perdidos" - que mesmo sendo localizados, por apresentarem condições tão precárias, são muitas vezes irrecuperáveis - com que se depara no decorrer de suas buscas. Tudo isso, em função do reduzido espírito de conservação da nossa histónia.

Os arquivos referentes à memória" das escolas católicas pesquisadas praticamente inexistem, por exemplo. Essa história está mesmo na memória sustentada pela lembrança daquelas pessoas que participaram de tais processos e se apropriam dela como se fosse uma história de interesse exclusivamente particular.

Frente a tal panorama, a solução foi investir-se de detetive e sair à cata do material indispensável, procurando um por um os dados e informações, para obter as fontes e os recursos necessários à reconstituição do fenômeno em estudo. Ou seja, às vezes o pesquisador precisa assumir atribuições que, em princípio, não fazem parte da sua competência, o que aliás é bem aceito por ele, quando consegue atingir os principais objetivos visados com a pesquisa.

Essa tem sido a regra mantida no decorrer desta investigação: muito tempo, muita imaginação e perseverança estão sendo dispendidos, a fim de obter as referências necessárias à reconstituição da trajetória do processo de formação proposto pelas escolas de ofício católicas em estudo, a fim de que o mesmo deixe de apresentar uma memória de caráter individual ou particular e tenha condições de se transformar - sem perder a sua singularidade - em memória social.

Tais preocupações são reforçadas pelo alerta de Bloch ao observar que a ignorância do passado, além de prejudicar o conhecimento do presente, compromete também a própria ação no presente. Logo, o processo de reconhecimento é fundamental à dinâmica do próprio fenômeno em análise e ao contexto mais amplo em que o mesmo está inserido.

Em vista disso, consolidar uma linha de pesquisa que pretende resgatar a memória social pode representar, efetivamente, uma forma de qualificar as ações e políticas que estão sendo implementadas na atualidade e que têm a finalidade de formar 0 cidadão para 0 ano 2000. ${ }^{\circ}$ Com esse intuito, através de um conjunto de ações que vem sendo empreendidas desde 1988, busca-se uma apropriação capaz de "ajudar a preparar o que há de ser". Assim, pretende-se atingir uma

5 Essa questão está mais desenvolvida em DESAULNIERS, Julieta B. Ramos. "Memória social e cidadania" - texto apresentado no III Congresso Iberoamericano de História de Educação Latinoamericana, realizado em junho/1996, Caracas/Venezuela, a ser publicado no Cademo CEDES, SP: Papirus, em 1997.

- Importantes referências sobre essas questões em MAGALHÃES, Justino. "Contributo para a história das instituições educativas - entre a memória e o arquivo". Material gentilimente cedido pelo autor (Texto mimeografado, 1995).

- Projeto Integrado (1994), op. cit., p. 4.

- NÓVOA, Antônio. Inovação e história da educação. Teoria \& Educação. Porto Alegre: Ed. Pannônica Ltda., n. 6, 1992. p. 219. 
"apropriação interveniente do passado", ao se captar a evolução das escolas católicas investigadas e, dessa maneira, "ajudar o homem a pensar-se no mundo e a intervir de forma mais avisada e inteligente na construção de uma sociedade diferente"."

Comentam-se, a seguir, as principais iniciativas que estão sendo sistematizadas através das pesquisas em andamento, para se garantir a socialização do fenômeno em análise, possibilitando assim o re-conhecer das identidades individuais desses processos - tanto por elas próprias ao se resgatar aspectos importantes da história do seu principal campo social de atuação, quanto por parte do contexto mais amplo que o constitui - enquanto significativas expressões da memória coletiva.

\section{Banco de Dados Informatizado}

Essa iniciativa constitui o ponto de confluência dos vários subprojetos desenvolvidos junto à linha de pesquisa aqui referida, garantindo assim a utilização mais ágil dessas informações pelas pessoas interessadas no assunto. ${ }^{50}$

O Banco de Dados está sendo montado com base nas principais categorias e dimensões que operacionalizam os pressupostos teóricos em que se sustentam as pesquisas, procurando evidenciar a estrutura e a organização do campo religioso no RS, os seus principais empreendimentos voltados à formação, bem como as ações e estratégias que foram sendo implementadas pelos seus representantes para garantirem a dinâmica de tais processos, no decorrer dos últimos séculos.

Também, as possibilidades de socialização dos resultados do conjunto de estudos e pesquisas sistematizados até o momento ampliam-se significativamente a partir do Projeto Integrado, visto que diversas atividades da pesquisa envolvem diretamente três instituições universitárias que, por sua vez, estabelecem contatos com outras instituições, em que o Banco de Dados (que inclui as diferentes fontes consultadas, independentemente do seu suporte - fotografia, documentos, entrevistas -, facilitando a elaboração de Guia Preliminar de Fontes, Álbum Fotográfico, Catálogo Temático), por se constituir no ponto de confluência entre os vários subprojetos em andamento, representa um excelente instrumento de recuperação e de socialização da memória social.

\section{Exposição}

Em comemoração ao centenário da escola de ofício católica Pão dos Pobres, caso exemplar dentre as que se situam no estado do Rio Grande do Sul, organizou-se a exposição que buscou resgatar a sua trajetória "através de fotos, objetos, depoimentos e ambientação", a qual significou "um inventánio da memória social contida nos vestígios preservados pela Obra"."

49. Idem, p. 213 e 216.

so Consideraçōes feitas pela bolsista Maria Alice Canzi, ao expor as atividades que desenvolveu junto ao subprojeto "O campo religioso no RS e a formação para o trabalho", no VII Salão de Iniciação Cientifica, UFRGS, 1995, p. 2.

61 Idéias de STEPHANOU, Maria, ao apresentar essa iniciativa em material de divulgação, enquanto consultora que acompanhou a realização desse evento e membro da equipe do Projeto Integrado "Urbanidade E Cidadania", op. cit. 


\section{Museu Pedagógico}

A exposição sobre o Pão dos Pobres é o passo inicial para organização e montagem de um museu sobre as escolas de ofício católicas do Rio Grande do Sul, que também terá como referência os pressupostos que orientam as investigações em andamento, tendo como objetivos: ${ }^{.52}$

- recolher/preservar a memória social das escolas de ofício católicas do RS;

- reconstituir espaços/vivências da formação em escolas de ofício católicas do RS;

- reconstituir aspectos desses processos pedagógicos desencadeados no RS;

- resgatar sinais, vestígios do passado que contribuam para a elucidação do presente de tais escolas;

- fomentar iniciativas de preservação da memória social no RS;

- traduzir em linguagens diferenciadas os estudos desenvolvidos sobre a formação em escolas de ofício católicas do RS;

- delimitar os vários espaços e tempos de formação do cidadão e de constituição de cidadania, que foram construídos em tais escolas enquanto lugares.

\section{O Ensino e a Extensão}

O fenômeno investigado tem-se constituído a fonte principal para as inúmeras atividades que desenvolvo enquanto professora universitária e pesquisadora na área das Ciências Humanas e Sociais, tais como: atualização permanente das disciplinas que ministro; organização de cursos de extensão universitária; aprimoramento dos instrumentais utilizados em pesquisa e das monografias e dissertações de mestrado que oriento; qualificação dos intercâmbios entre pesquisadores nacionais e internacionais; produção de artigos para revistas especializadas; elaboração de trabalhos para congressos nacionais e internacionais; palestras proferidas sobre essa questão nas próprias escolas católicas; traduções, organização de publicações e de missões de trabalho de professores estrangeiros...

Enfim, todo esse conjunto de estudos e iniciativas dinamizados pelo processo de pesquisa em desenvolvimento, representam importantes ocasiões para confrontar os saberes que vêm sendo produzidos, o que tende a instigar a reconstituição da memória de um fenômeno que é considerado essencial na atualidade: a formação do trabalhador enquanto cidadão.

Ainda, o fato de tais pesquisas sustentarem-se em dispositivos que podem estimular análises comparativas garante também um maior rigor científico, já que aumenta o seu "fôlego" para reconstituir mais registros dos vestígios dessa história. E, assim, ampliam-se também os espaços de resgate da memória social e de construção da cidadania.

62 Tais referências foram retiradas de GONZAGA, Duicemara Guazzelli, mencionadas no subprojeto sobre o Museu Pedagógico das Escolas de Oficio Católicas, RS, 1995, p. 2, que está sob minha coordenação. 


\section{4- Considerações finais}

Parece não restar muita dúvida quanto à importância e o significado para o campo acadêmico em particular, e para sociedade em geral, de uma formação dinamizada pela e para a pesquisa. Mas é possivel que restem ainda muitas indagações quanto aos meios e formas a serem utilizados na operacionalização de tal processo.

Nesse sentido, é possível que seja bem complicado chegar-se a um consenso. Mesmo assim, em termos gerais, ficou evidenciado nesta exposição que produzir pesquisa científica e o respectivo pesquisador - o que é da competência da universidade - supõe a utilização de parâmetros tanto para a produção da ciência, os quais já existem há mais de dois séculos, como para a formação do pesquisador.

Além disso, procurou-se insistir no fato de que desenvolver pesquisa - a possibilidade de avanço da ciência e do capital científico que distingue o mundo acadêmico - implica necessariamente a produção intencionada dos seus agentes, os pesquisadores. Ainda, esse processo, para ser instaurado demanda uma dinâmica que seja capaz de, através de uma série de rupturas, produzir uma postura junto ao formado, que se aproxime minimamente das disposições que caracterizam o habitus acadêmico.

Também, foi assinalado aqui que esse empreendimento é complexo e exigente em relação a todos os agentes, direta ou indiretamente, associados a ele. Assim, espera-se que, em alguma medida, tenha ficado demonstrado que apesar de ser uma empreitada que não tolera protelações intermináveis, constitui a alternativa que dispõe das possibilidades para se construírem novos pesquisadores, já que ao se apoderarem dos instrumentos indispensáveis ao ato de pesquisar, terão incorporado as disposições que são capazes de assegurar a competência mínima necessária para a produção de novos saberes científicos. Desse modo, então, é possivel promover o fortalecimento do meio acadêmico e, ao mesmo tempo, oferecer mais elementos para 0 aprofundamento da cidadania, pois todo esse processo de formação por e pela pesquisa tem as suas bases na reconstrução da memória social. 